\title{
Neolithic LBK Intrasite Settlement Patterns: A Case Study from Bylany (Czech Republic)
}

\author{
Petr Květina and Markéta Končelová \\ Institute of Archaeology of the Academy of Sciences of the Czech Republic, Letenská 4, Praha 1-Malá Strana, \\ 11801 Prague, Czech Republic
}

Correspondence should be addressed to Petr Květina; petrkvetina@yahoo.com

Received 21 August 2012; Accepted 20 December 2012

Academic Editor: Ravi Korisettar

Copyright (C) 2013 P. Květina and M. Končelová. This is an open access article distributed under the Creative Commons Attribution License, which permits unrestricted use, distribution, and reproduction in any medium, provided the original work is properly cited.

\begin{abstract}
This paper could also be a contribution to a new concept for understanding space and time in Neolithic settlements. We abandoned the methodological concept of construction complexes of houses and used individual archaeological features as the basic analytical unit. The analysis of quantitative correlations of decorative style conducted on this basis produced five style groups; four of these belonged to a LBK style, and it was these that were spatially distinct at the Bylany settlement. The discovered spatial patterns of style correspond in general to the existing chronology of the site. This means that chronological horizons understood both as intervals on the time axis and as geographic units are not dependent on "construction complexes" or even on individual houses. The value of this study does not lie in a more detailed chronological division of the Neolithic settlement at Bylany, but in a confirmation of the robustness of its existing form; the study also draws attention to a possible problem in the concept of construction complexes.
\end{abstract}

\section{Introduction}

The oldest agricultural population of Central, and partly also Western, Europe is archaeologically tied to the Linear Pottery culture (LBK-Linearbandkeramik) and covers the period $5500-5000 \mathrm{BC}$. The term is derived from the typical method used to decorate pottery, namely, the form of incised lines or bands. The basic archaeological manifestation of this period comes in the form of remains of settlements. This originally included various numbers of longhouses made of wooden pole structure with walls of wattle and daub. However, all that remained of these were postholes and foundation trenches. The length of these houses ranged usually from four to fifty metres, but their floor level was not discovered. The question remains as to whether the floors were situated at the level of the original terrain or whether an elevated platform was involved $[1,2]$. The archaeological finds therefore do not come from the interior of the houses, but from pits surrounding them. The pits were both large (covering dozens of square meters) and smaller-mainly as longer pits lining the west and east walls of the original houses. Extremely large pits without a direct spatial relationship to the houses contained a conglomerate of artefacts originating in an apparently long chronological interval (up to 500 years). On the other hand, the long pits located near the houses contain objects whose dating falls into substantially shorter intervals.

It is significant that finds from these pits are normally regarded as representing the direct image of the residents of a particular house, which is clearly reflected in classic $[3,4]$ or recent works on the subject $[5,6]$. However, this need not necessarily to be the only methodological model. The aim of this work is to verify the existing time-spatial model of Neolithic settlement. The work is based on a quantitative analysis of the style of linear decoration and pottery technology performed on the level of archaeological features/contexts.

\section{The Site of Bylany and the "House Complex" Model}

The results of this paper are based on the long-term archaeological project executed at Bylany in the Czech Republic. Along with Eythra, Langweiler 8, Olszanica, and Ulm-Eggingen, the Neolithic site of Bylany is one of the largest LBK settlements in Central Europe. The three unconnected 


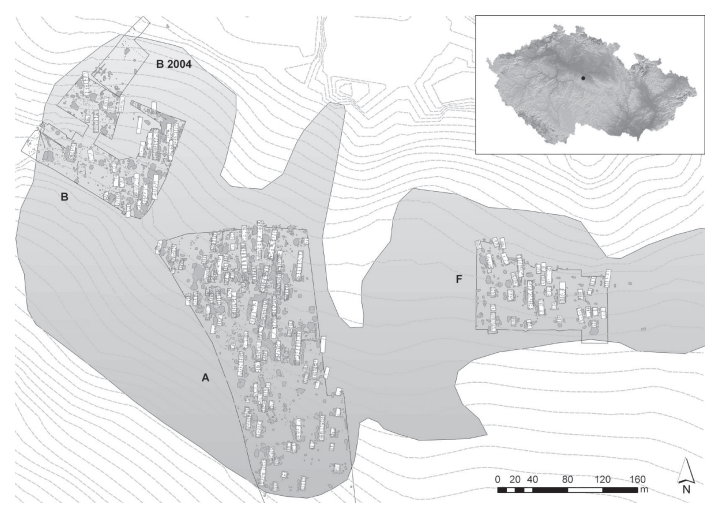

FIgURE 1: The status of archaeological excavations of the Bylany 1 area. The grey area marks the total area of 21 ha inhabited during the Early Neolithic period.

areas studied during the course of the terrain seasons of archaeological excavations at Bylany were labelled sectors A, $\mathrm{B}$, and $\mathrm{F}$ (Figure 1). A total of 1,045 archaeological features and 144 more or less preserved ground plans of long houses were studied.

The mutual ties between the houses and the pits were, as at many other sites, resolved based on their mutual spatial positions. This led to the setting of basic chronologicalspatial units-the "house complex." The core of the house complex is the ground plan of the house composed of postholes and adjacent pits situated along the walls of the house at a maximum distance of five metres. This distance criterion was established on the basis of empirical experience with their location throughout the settlement area [7]. However, the purpose of these adjacent pits has not yet been definitively clarified. Most frequently it is assumed that they are clay pits that primarily served as a source of house material for building the house. The pits were then filled, both with settlement refuse from around the house, as well as by natural runoff [8]. The time interval in which the original pit was filled by either intentional or natural processes cannot be determined. Regardless of these facts, the archaeological finds from Neolithic settlements are usually always analysed in relation to the original houses.

Archaeological finds from the Bylany LBK settlements make up a large assemblage of artefacts that includes pottery fragments, chipped stone (flints), polished stone (axes and adzes), whetstones (abrading, smoothing, and polishing tools), grinding slabs, and handstones. The most significant in terms of pastsocial relations and of the utmost importance for this paper is the assemblage of pottery finds containing more than 76,000 fragments.

\section{Linear Pottery Decoration Style}

Each pottery fragment is the potential bearer of numerous characteristics, of which the category of engraved linear decoration forms the basis for a relative chronology for Bylany and LBK cultures as a whole. Naturally, linear decoration is not homogenous from an analytical perspective; instead, it is composed of several levels that are typically conceived in different ways by individual authors $[9,10]$. For a basic impression it is enough to divide linear decoration on pottery into three levels: motif, style, and elements.

Motif is the result of the composition of decoration on the body of the entire vessel [9]. In addition to the main motif the vessel can also include secondary, dividing, and line decoration beneath the rim of the vessel. The identification of the motif requires the preservation of a larger part of the vessel, which in the case of the material from settlements is not very common.

Style in the case of LBK pottery in Bylany is defined by the technique for producing the decoration. A total of fourteen styles produced by one, or a combination of techniques have been identified: engraved broad grooves $(b, g)$, engraved lines $(d, d 30)$, engraved bands filled with punctures ( $a 12$, $a 13, a 20, a 30)$, engraved lines with punctures (i.e., "musical notes") (e10, e20, e30), dense punctures on a very fine engraved line $(z)$, independent punctures (et), and engraved lines with adjacent punctures ( $t h$, Figure 2 ). The concrete style can also be relatively reliably identified on individual pottery fragments, and hence, the decorative level can also be distinguished on settlement material.

Elements of linear decoration are the basic building blocks of style [11]. For example, the descriptive system for Bylany site contains a total of 189 characters. While the large number of characters in the descriptive system apparently facilitates an exact evaluation of decoration, it also introduces the problem of artificial variability into the analysis. To a great extent the created characters do not reflect the intentional stylistic variety of the decoration [12].

The selection of the level of linear decoration for the intended purpose of reevaluation of the time-spatial sequence of the Neolithic settlements is influenced by the aforementioned criteria for identification and interpretive potential: motifs are essentially unidentifiable on the fragmentary material from the settlement, and decorative elements are purely an "etic" and outsider categorisation [13]. To solve this problem we therefore chose the middle category of decoration, which we label as style (Figure 2).

The specific frequency of decorative style on pottery specimens shows an extremely uneven distribution: while certain styles are very frequent $(d 12, e 10, e 0)$, others occur only rarely $(z, b, d 30, t h, a 30$, and et, Table 1$)$. There is a problem with the clear identification of the $e 0$ style: the given category was created to classify fragments for which a more detailed categorization under the character " $e$ " is not possible due to their fragmented condition. It became apparent during the course of the analyses that the $e 0$ style does not form any significant correlation and occurs along the entire spectrum of the matrix. For these reasons a decision was made to omit the $e 0$ style from the analysis. In addition to the decorative styles of Linear Pottery, an assemblage of pottery decorated in Stroked Pottery Ware (STK) style was also included in the analysis, even though this involves a decoration technique that did not take place at the same time. If more than a quarter of the assemblage features this decoration, it will be interesting to determine its correlative relationship to LBK decorative styles, both from a quantitative and spatial perspective. Linear Pottery culture decoration makes up 68\% 


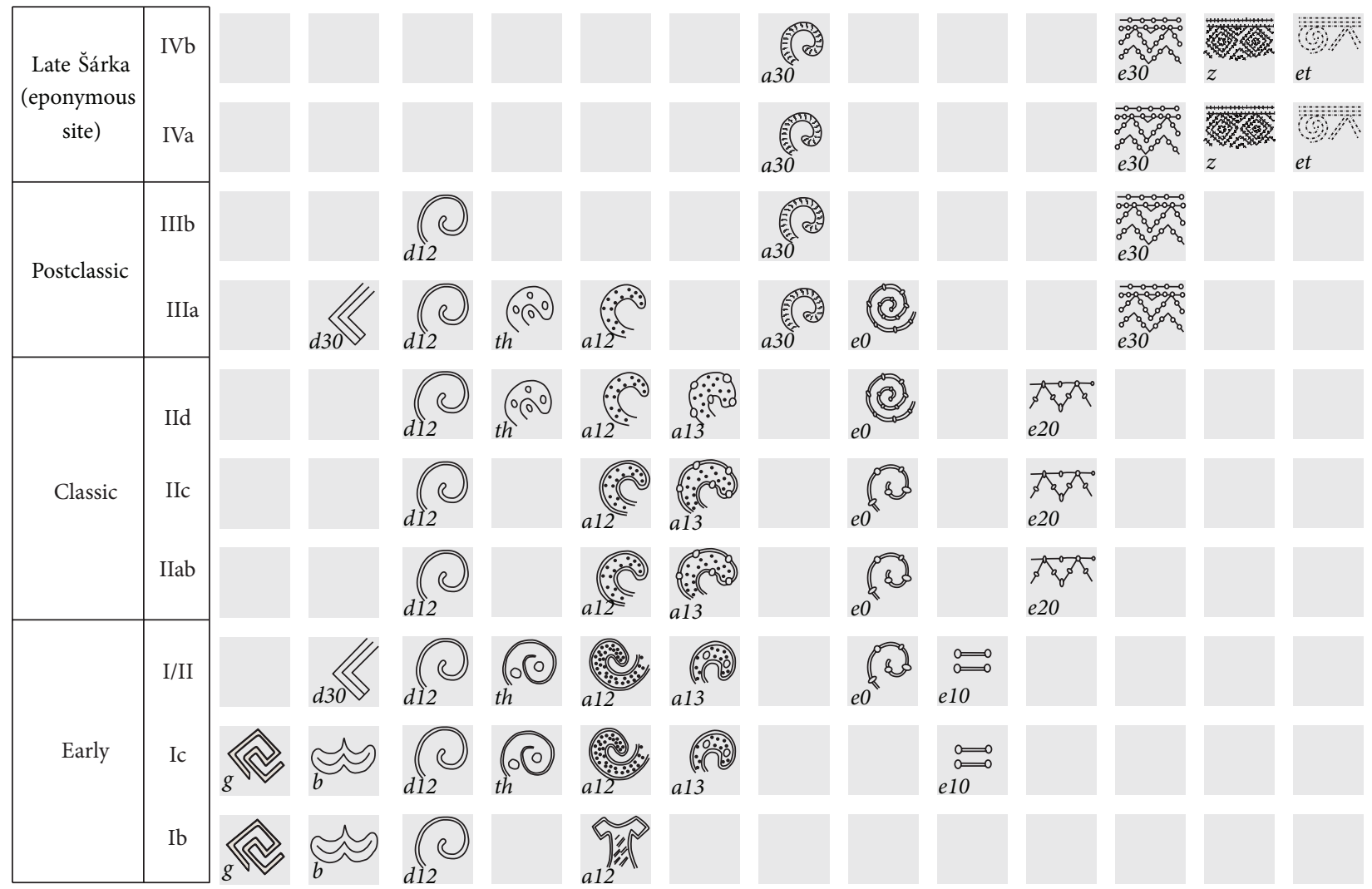

FIgURE 2: Styles of linear decoration in the chronological order of LBK culture.

TABLE 1: Frequency and relative frequency of styles of LBK pottery units at Bylany.

\begin{tabular}{|c|c|c|c|c|c|c|c|c|c|c|c|c|c|}
\hline & $\begin{array}{l}\text { (?) } \\
d 12\end{array}$ & $\begin{array}{l}00 \\
010\end{array}$ & 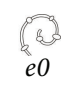 & $\begin{array}{l}\text { a12 } \\
\text { ic }\end{array}$ & $\begin{array}{l}\text { Fan } \\
e 20\end{array}$ & $\begin{array}{l}\text { 苓 } \\
e 30\end{array}$ & $g$ & $\begin{array}{l}\text { (i) } \\
a 13\end{array}$ & $\underset{d 30}{\mathbb{W}}$ & 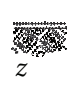 & $\begin{array}{l}\text { (6) } \\
\text { th }\end{array}$ & 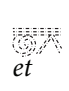 & $\begin{array}{l}10 \\
a 30 \\
a\end{array}$ \\
\hline$n$ & 7699 & 2970 & 2619 & 1681 & 1128 & 1042 & 263 & 434 & 106 & 144 & 63 & 28 & 35 \\
\hline$f(\%)$ & 42,3 & 16,3 & 14,4 & 9,2 & 6,2 & 5,7 & 1,4 & 2,4 & 0,6 & 0,8 & 0,3 & 0,2 & 0,2 \\
\hline n selection Q25-Q90 & 3735 & 1449 & 1259 & 724 & 549 & 601 & 219 & 196 & 74 & 70 & 46 & 24 & 17 \\
\hline$f(\%)$ select. Q25-Q90 & 41,7 & 16,2 & 14,0 & 8,1 & 6,1 & 6,7 & 2,4 & 2,2 & 0,8 & 0,8 & 0,5 & 0,3 & 0,2 \\
\hline
\end{tabular}

of the total of all decorated Neolithic pottery fragments, while Stroked Pottery Ware decoration makes up 32\%.

\section{Quantitative and Spatial Correlations of Pottery Decoration Style and Technology}

Unlike prior attempts, we abandon heretofore standard methodological schemes in which the formal and spatial characteristics of artefacts are grouped into a single analytical matrix (the "house complex" concept). In the given case formal characteristics are understood as information about the style of linear decoration on pottery vessels. Spatial characteristics are understood as data on the placement of artefacts and their formal attributes within the Neolithic settlement area, especially with regard to the ground plans of the long houses.

The applied methodology is based on the search for a quantitative correlation between individual linear decoration styles and, subsequently, between archaeological features. Discovered correlation trends are highlighted on the site map as a certain form of validation. Due to the excessive size of the data matrix, the use of a simple correlation technique is not effective. Instead, we utilised two multivariate statistical techniques: Detrended Correspondence Analysis (DCA) and Principal Component Analysis (PCA) [14, 15].

The result of statistical analyses is a total of five components extracted from the matrix (Table 2) and which collectively encompass $58 \%$ of the assemblage's variability. Each component represents and defines a specific style or its group (Figure 3). This result must then be validated, which means searching for confirmation of the defined groups of styles using an external quantity not previously used in the analysis.

The validation of the quantitative correlations of individual variables (linear decoration style) was conducted by means of a spatial illustration of the factor score values. A 


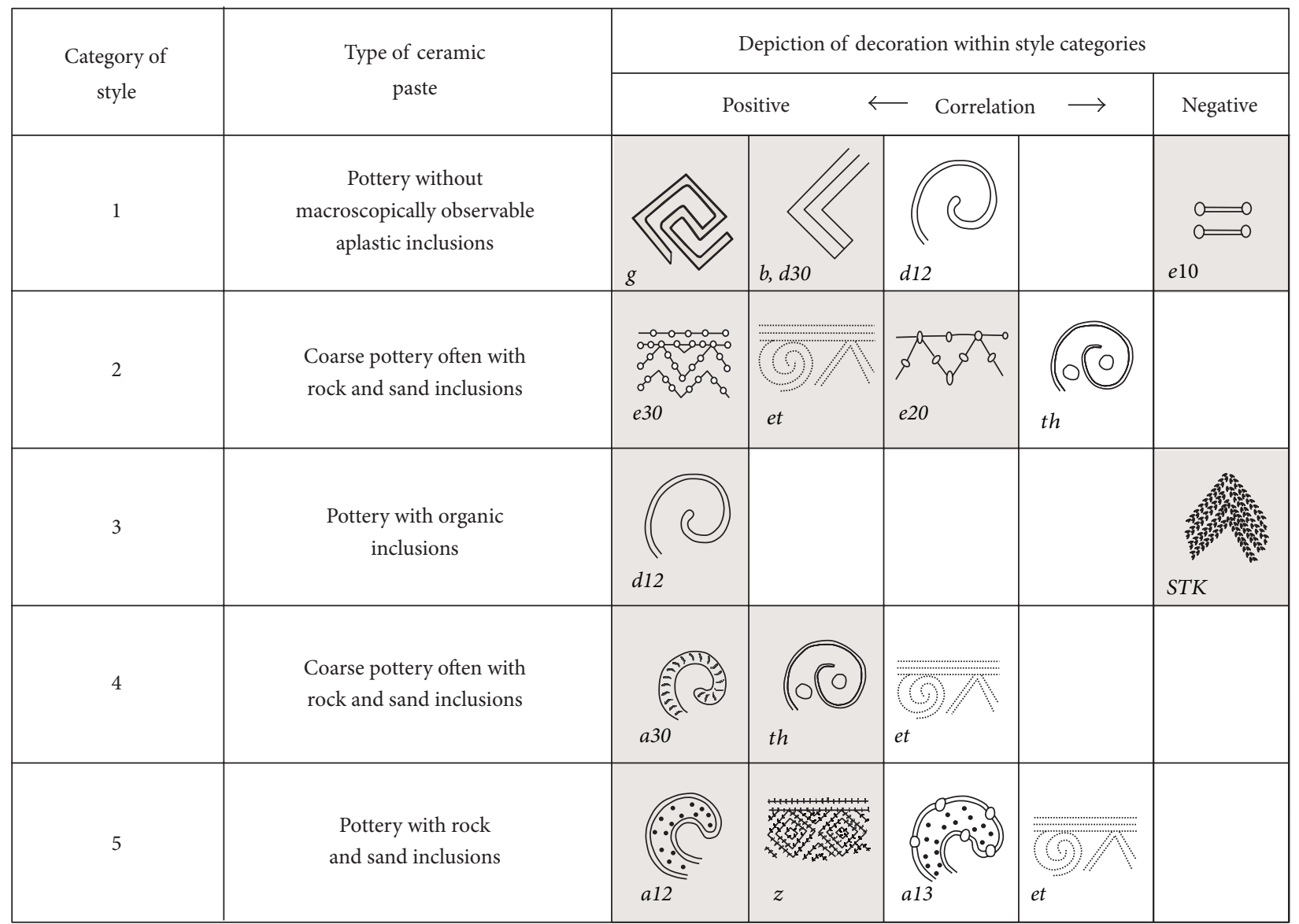

FIGURE 3: Technological properties (ceramic paste used in the manufacture of pottery) are correlated with five stylistic categories of Neolithic LBK pottery decoration.

TABLE 2: PCA result: five extracted components expressing the degree of correlation of individual styles and defining style groups. Extracted components of covariate matrix with eigenvalue over 1. Omitted variable: $e 0$.

\section{Rotated Component Matrix}

\begin{tabular}{|c|c|c|c|c|c|}
\hline \multirow{2}{*}{ Style } & \multicolumn{5}{|c|}{ Component } \\
\hline & 1 & 2 & 3 & 4 & 5 \\
\hline Eigenvalue & 1,930 & 1,728 & 1,484 & 1,327 & 1,125 \\
\hline$\%$ of variance & 36,8 & 14,6 & 10,6 & 9,1 & 7,7 \\
\hline e10 &,- 737 &,- 142 & ,237 & &,- 158 \\
\hline$g$ & ,692 &,- 202 & 137 & &,- 266 \\
\hline$b d 30$ & ,539 & & , 189 & & \\
\hline$a 13$ &,- 381 &,- 318 & ,212 & ,131 & ,200 \\
\hline e30 & &, 810 & & &,- 102 \\
\hline et & & ,633 & & ,193 & ,128 \\
\hline$e 20$ &,- 356 & ,456 & &,- 196 &,- 333 \\
\hline stk & ,129 &,- 198 &,- 924 & & \\
\hline$d 12$ & ,205 &,- 191 &, 735 &,- 108 & \\
\hline$a 30$ & & & & ,823 & \\
\hline th & & ,292 & & ,780 & \\
\hline a1220 &,- 147 &,- 107 & ,162 & &, 742 \\
\hline$z$ & & & & & ,688 \\
\hline
\end{tabular}


factor score is data assigned to each entity in the analytical matrix for all of the extracted components. The factor score value expresses the degree of correlation of the given entity with respect to each of the calculated trends of variable correlation. The higher the numerical value of the factor score of the context for some of the components, the more the trend of the specific stylistic correlation expressed by this component is typical for the given context. As stated above, each of the determined components (correlation trends) refers to a style group of linear decoration. Projecting factor score values on the site map also revealed that the determined trends are spatially distinct (with the exception of the fifth component linked to STK, which does not form an independent spatial trend). It is therefore possible to state that external evidence established that the groups of LBK styles are not defined solely on the basis of formal pottery qualities, but also on their spatial attributes (Figure 4).

Moreover, in order to confirm the reliability of discovered trends in pottery decoration, we analysed their correlation with certain technological pottery properties. This specifically involved macroscopic evaluation of ceramic paste used in the manufacture of pottery [16]. The results confirmed the existence of 5 groups that correspond with the stylistic trends of Linear Pottery decoration (Figure 3). These stylistic trends in LBK pottery can be projected onto a time line, where they acquire the appearance of intervals and can also be viewed as geographical units with a hypothetical reference to past social ties. Primarily, the demonstrated technological differences between individual style groups can also point to past social identity [17].

\section{Chronology and Settlement Spatial Management in the LBK}

Results of analyses presented previously directly involve the question of interpretation of the original form of the living Neolithic LBK settlement. During the many large-scale excavations commenced in the 1950s and 1960s, it was soon recognized that the great size of the settlement with a large number of house ground plans was only illusory [2]. Only a few of the buildings were ever truly synchronous (in many cases this involved the spatial redeposition of a single house) [18]. An explanation of the periodic relocation of houses and the absence of their reconstruction has its own theoretical development, a summary of which is beyond the scope of this work [19]. There is no doubt that it was long Neolithic houses that structured the original area of the living settlement, both from an economic and subsistence perspective.

Two theoretical models depict the hypothetical appearance of the Neolithic settlement as social wholes. The first works with the concept of an integral settlement with a population of descendants [3]. The second model imagines that Neolithic settlements were made up of individual farmsteads (ward model, hofplatz) that stood either alone or in loose agglomerations with others [20]. Based on the reinterpretation of research results at Aldenhovener Platte (Germany) a further model was recently formulated (the row settlement model, Zielensiedlungsmodel). Its author assumes that the Neolithic settlement here had the appearance of

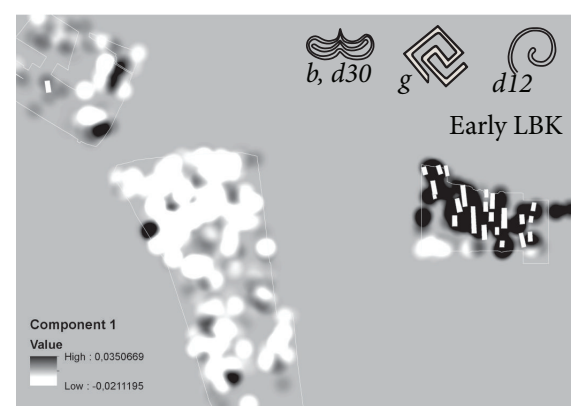

(a)

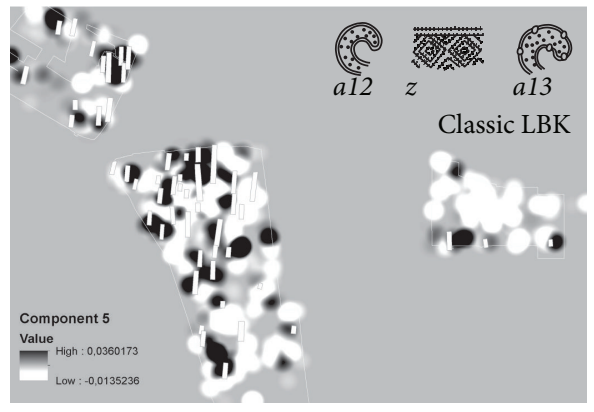

(b)

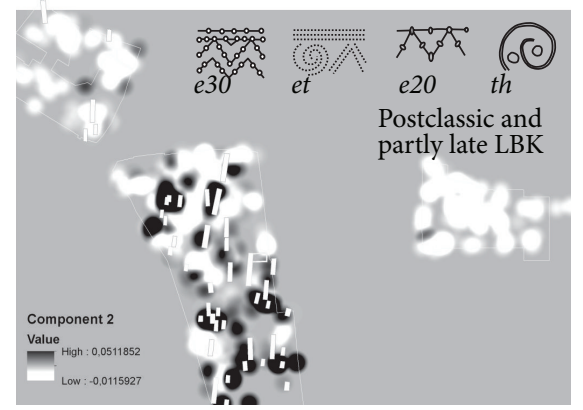

(c)

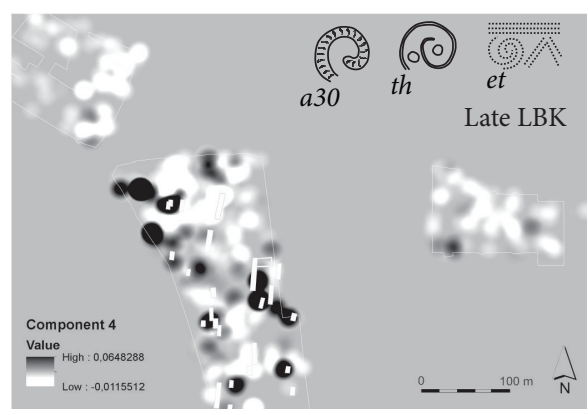

(d)

FIGURE 4: LBK decoration style groups in the Bylany Neolithic settlement area.

a sequentially developed row of houses, always with one markedly longer house [21]. What these three hypotheses have in common is the premise of the "house complex," which states that the contents of the pits in the immediate vicinity of the houses reflect activities connected with the inhabitants of the house and, hence, also date them. Chronology, functional analyses and subsistence are all based on the assumption of the direct relation between the settlement refuse deposited 
near the house and the period in which the house was inhabited.

The results of this work could testify to the need for a new concept of grasping spatial and time-related elements of Neolithic settlements. Here we put aside the methodological concept linking pits with the ground plans of structures ("house complex" model), and we attributed the basic analytical unit to individual pits. The conducted analysis of quantitative correlations of decoration style (which was based on this) linked with the ensuing study of technological properties of pottery then demonstrated five style groups, four of which belong to the LBK style, and it is these that are spatially distinct within the Bylany settlement (Figure 4). At the same time, the revealed spatial patterns of style correspond overall with the primary chronology of the settlement on the level of individual LBK stages that have already been published [11]. This is noteworthy, especially taking into account the differing methodological bases of these schemes: all current chronology is defined on the basis of the house complexes; on the other hand, style groups in this work were generated by their exclusion. On a methodological level of Neolithic settlement studies, this means that even without the concept of the so-called "house complexes" it is possible to make out the local chronological development. This is important due to the fact that while the ground plans of Neolithic structures do form the basic structuring element of settlements, their original appearance, duration, and social interpretation, however, remain unanswered.

Trends in pottery decoration style are independent of house complexes, thus also of individual houses, and this independence does pose new questions in the theory of Neolithic settlement studies. Mainly, the direct reflection of the activities of original citizens impressed into the quantitative and spatial distribution of artefacts in settlements grounds can be put into question. Studies that take up a detailed analysis of the spatial placement of settlement refuse point out that artefacts are not structured only in connection with individual houses, but likely also with respect to the total area of the settlement in the given chronohorizon $[8$, $22]$. With respect to their type and number, the deposited artefacts more likely reflect in this concept the methods for handling refuse in the entire community instead of the activities conducted by a single settlement unit. It would seem that the Neolithic settlement functioned from the perspective of refuse deposition as a conglomerate of inhabited and abandoned houses, a notion that would also correspond with some of the results of ethnoarchaeological excavations [23, 24].

\section{Acknowledgment}

This work was accomplished with the support from the Project no. P405/11/1590 of the Czech Science Foundation.

\section{References}

[1] D. W. A. Startin, "Linear Pottery Culture houses: reconstruction and manpower," Proceedings of the Prehistoric Society, vol. 44, pp. 143-161, 1978.
[2] A. Whittle, Europe in the Neolithic, Cambridge University Press, Cambridge, UK, 1996.

[3] B. Soudský, “The Neolithic site of Bylany," Antiquity, vol. 36, no. 143, pp. 190-200, 1962.

[4] J. Lüning, "Forschungen zur bandkeramischen Besiedlung der Aldenhovener Platte im Rheinland," in Siedlungen der Kultur mit Linearkeramik in Europa, J. Pavúk, Ed., pp. 125-156, Archäologisches Institut, Nitra, Slovakia, 1982.

[5] L. Hachem, "New observations on the Bandkeramik house and social organization," Antiquity, vol. 74, pp. 308-312, 2000.

[6] I. Pavlů, Life on a Neolithic Site, Archeologický Ústav, Praha, Czech Republic, 2000.

[7] B. Soudský and I. Pavlů, "The Linear Pottery Culture settlements patterns of central Europe," in Man, Settlement and Urbanism, P. J. Ucko, R. Tringham, and G. W. Dimbleby, Eds., pp. 317-328, Duckworth, London, UK, 1972.

[8] H. Stäuble, "Häuser, Gruben und Fundverteilung," in Ein Siedlungsplatz der Ältesten Bandkeramik in Bruchenbrücken, Stadt Friedberg/Hessen, J. Lüning, Ed., Universitätsforschungen zur Prähistorischen Archäologie 39, pp. 17-150, Habelt, Bonn, Germany, 1997.

[9] J. Rulf, Die Elbe-Provinz der Linearbandkeramik, Památky Archeologické-Supplementum 9, Archeologický Ústav, Praha, Czech Republic, 1997.

[10] P. Stehli, "Zeitliche Gliederung der verzierten Keramik," in Der Bandkeramische Siedlungsplatz Langweiler 8. Gemeinde Aldenhoven, Kreis Düren, U. Boelicke, J. D. Von Brandt, J. Lüning et al., Eds., pp. 441-482, Rheinland, Köln, Germany, 1988.

[11] I. Pavlů, J. Rulf, and M. Zápotocká, “Theses on the Neolithic site of Bylany," Památky Archeologické, vol. 77, pp. 288-412, 1986.

[12] J. Sackett, "Style and ethnicity in archaeology: the case for isochrestism," in The Uses of Style in Archaeology, M. W. Conkey and C. A. Hastorf, Eds., pp. 32-43, Cambridge University Press, Cambridge, UK, 1990.

[13] M. Harris, "History and significance of the Emic/Etic distinction," Annual Review of Anthropology, vol. 5, pp. 329-350, 1976.

[14] M. J. Baxter, Exploratory Multivariate Analysis in Archaeology, Edinburgh University Press, Edinburgh, UK, 1994.

[15] L. R. Binford and S. R. Binford, "A preliminary analysis of functional variability in the Mousterian of Levallois facies," American Anthropologist, vol. 68, no. 2, pp. 238-295, 1966.

[16] I. Pavlů and M. Zápotocká, Bylany. Katalog A-1, Archeologický Ústav, Praha, Czech Republic, 1983.

[17] M. Dietler and I. Herbich, "Habitus, techniques, style: an integrated approach to the social understanding of material culture and boundaries," in The Archaeology of Social Boundaries, M. T. Stark, Ed., pp. 232-269, Smithsonian Institution, Washington, DC, USA, 1998.

[18] J. Last, "The residue of yesterday's existence: settlement space and discard at Miskovice and Bylany," in Bylany Varia 1, I. Pavlü, Ed., pp. 17-45, Archeologický Ústav, Praha, Czech Republic, 1998.

[19] R. Bradley, "Long houses, long mounds and Neolithic enclosures," Journal of Material Culture, vol. 1, no. 2, pp. 239-256, 1996.

[20] J. Lüning, "Frühe Bauern in Mitteleuropa im 6. und 5. Jahrtausend v. Chr," Jahrbuch des Römisch-Germanischen Zentralmuseums Mainz, vol. 35, no. 1, pp. 27-93, 1988. 
[21] O. Rück, Neue Aspekte und Modelle in der Siedlungsforschung zur Bandkeramik. Die Siedlung Weisweiler 111 auf der Aldenhovener Platte, Kr. Düren, Internationale Archäologie 105, Marie Leidorf, Rahden, Germany, 2007.

[22] P. Kvertina, "The spatial analysis of non-ceramic refuse from the Neolithic site at Bylany, Czech Republic," European Journal of Archaeology, vol. 13, no. 3, pp. 336-367, 2010.

[23] M. Deal, "Household pottery disposal in the Maya highlands: an ethnoarchaeological interpretation," Journal of Anthropological Archaeology, vol. 4, no. 4, pp. 243-291, 1985.

[24] B. Hayden and A. Cannon, "Where the garbage goes: refuse disposal in the Maya Highlands," Journal of Anthropological Archaeology, vol. 2, no. 2, pp. 117-163, 1983. 

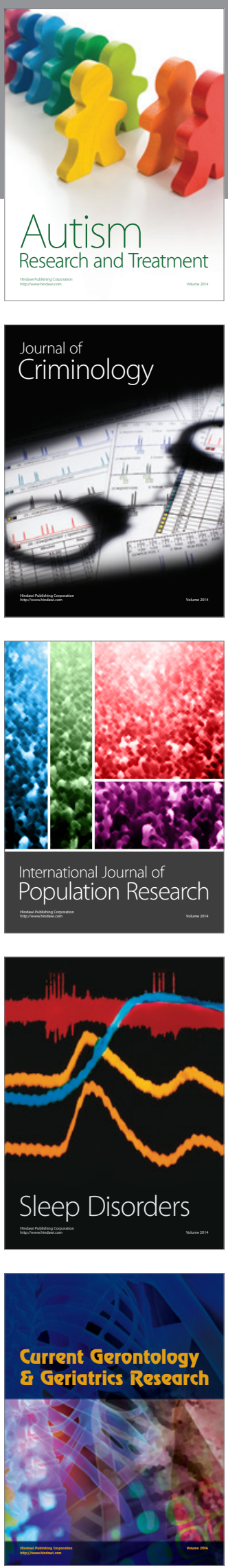
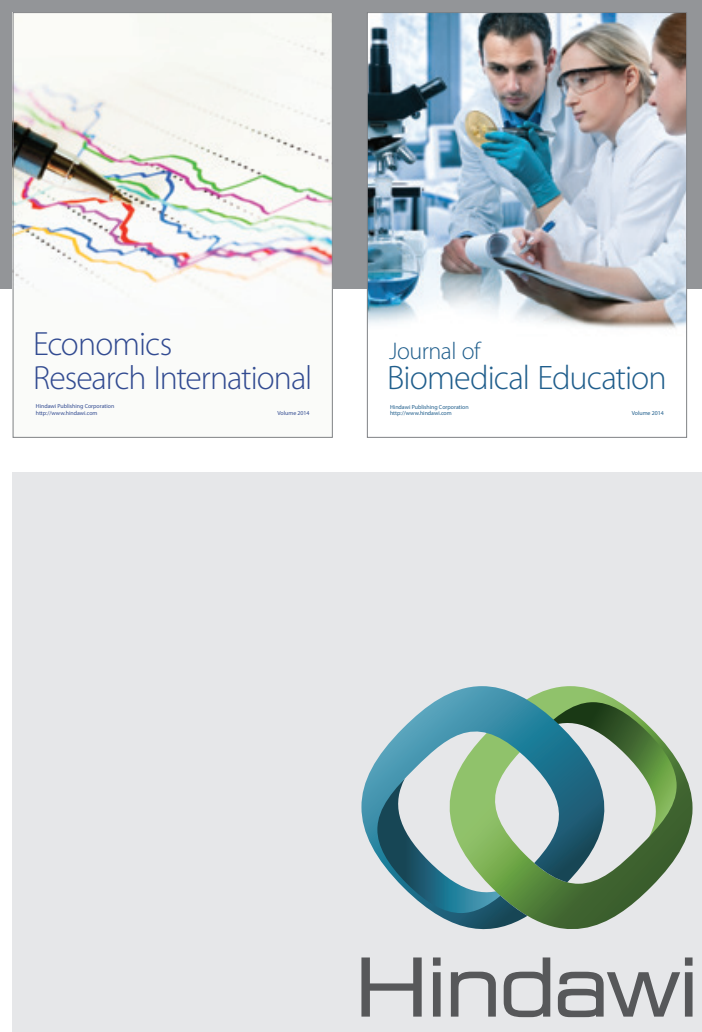

Submit your manuscripts at

http://www.hindawi.com
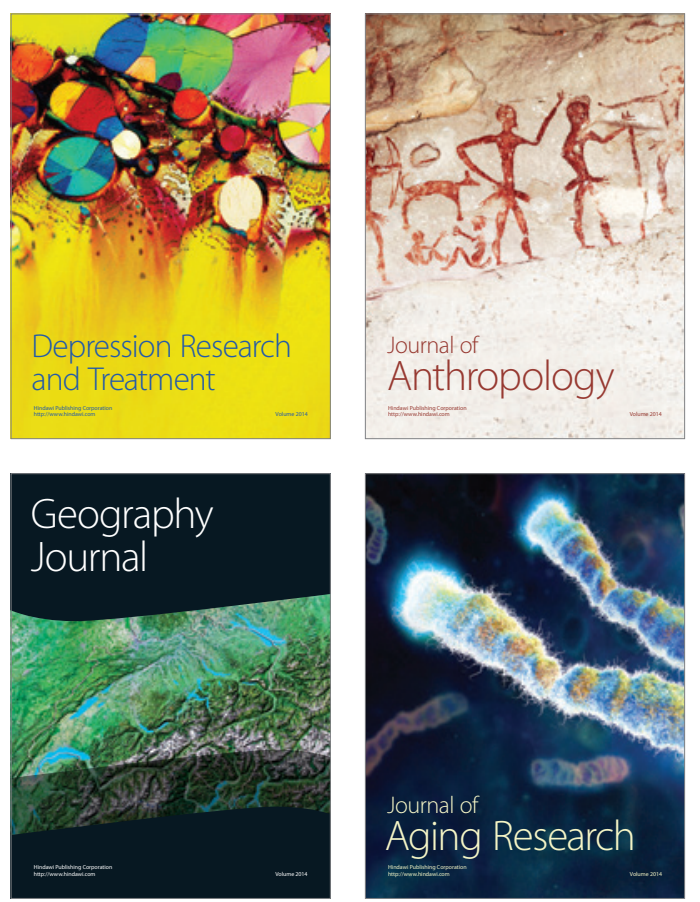
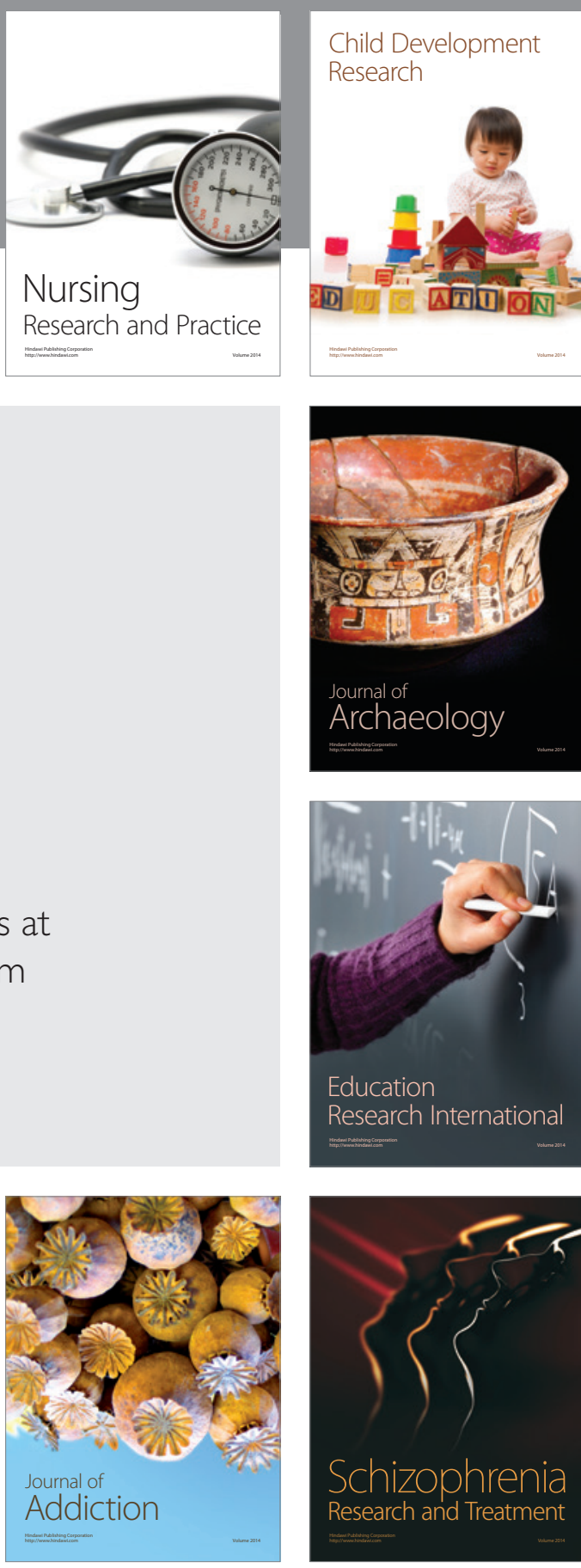

(D)
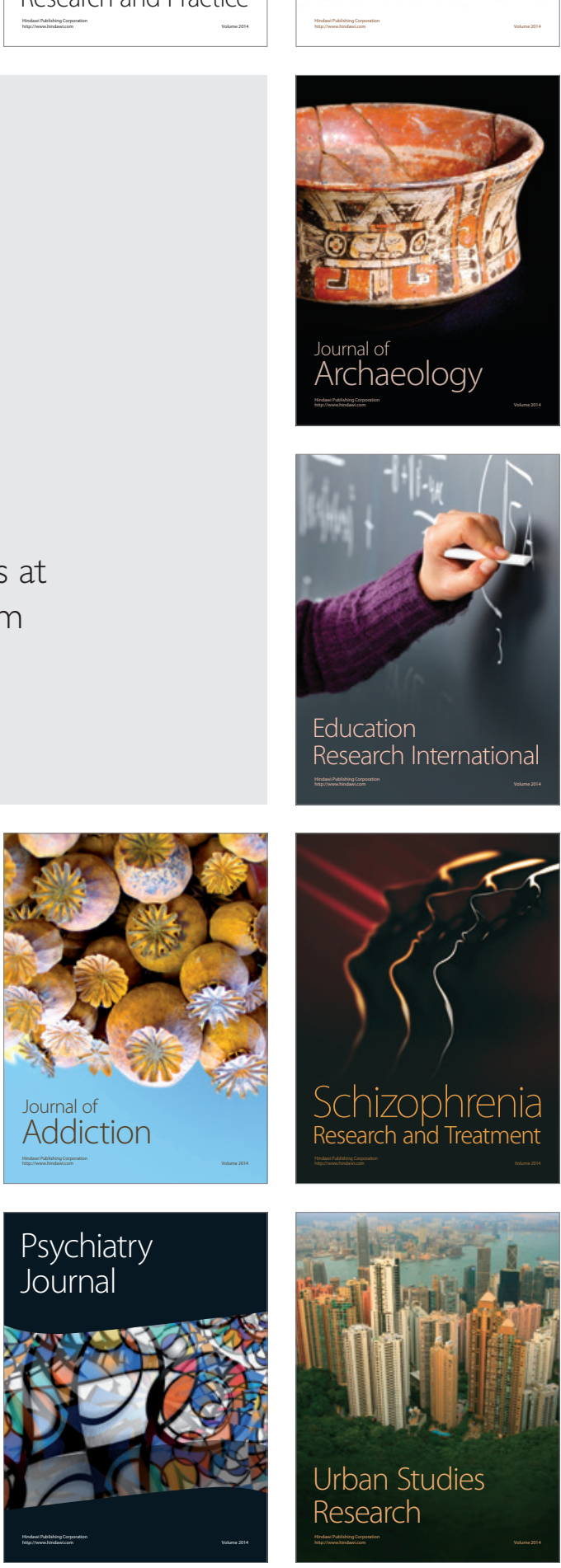